\title{
ON THE TEMPERATURE PROFILE AND THE AGE PROFILE IN THE CENTRAL PART OF COLD ICE SHEETS
}

\author{
By K. Philberth* and B. Federer \\ (Eidg. Institut für Schnee- und Lawinenforschung, Davos, Switzerland)
}

\begin{abstract}
The generalized Glen's law $\dot{\epsilon}=\dot{\epsilon}_{0} \tau^{n} \exp (k \theta)$ is used to calculate the horizontal and vertical velocity profiles and from these the temperature and age profiles of cold ice sheets. It is shown that, by substituting for $\theta$ a function increasing linearly with height, velocity profiles for all ice sheets are obtained which represent excellent approximations to the true ones, since, above a critical height $h_{\mathrm{c}}$ where the deviation from linearity becomes large, the influence of temperature on ice flow becomes negligible. In a comparison of the present theory with Robin's (1955) treatment a larger temperature difference $\Delta T$ of up to $30 \%$ is obtained. Furthermore the present theory yields an age considerably increased compared with Nye's model; e.g. more than $50 \%$ at a relative height of $h / H=0 \cdot 1$.

RÉsumé. Sur les profils de température et d'âge dans la région centrale des calottes glaciaires. La loi généralisée de Glen $\dot{\epsilon}=\dot{\epsilon}_{0} \tau^{n} \exp (k \theta)$ est employée pour calculer les profil de vitesse horizontale et verticale et, à partir d'eux, les profils de température et d'âge des calottes glaciaires froides. Il est démontré qu'on peut obtenir des profils de vitesse qui représentent des approximations excellentes des profils réels pour toutes les calottes, si l'on substitue à $\theta$ une fonction qui croît linéairement avec la hauteur au-dessus du lit rocheux. Au-dessus d'une hauteur critique $h_{\mathrm{c}}$, où la température réelle s'écarte de la linéarité, l'influence de la température sur le fluage de la glace est en effet négligeable. En comparant la présente théorie avec celle de Robin (1955) on obtient des différences de température $\Delta T$, qui peuvent être jusqu'à $30 \%$ plus grandes. La théorie permet en plus de calculer l'âge de la glace qui est considérablement supérieur à l'âge calculé d'après le modèle de Nye; par exemple il est plus de $50 \%$ supérieur à une hauteur relative $h / H=0 \cdot 1$ au-dessus du lit rocheux.

Zusammenfassung. Über das Temperatur- und Altersprofil des Eises im Zentralbereich kalter Eiskalotten. Die allgemeine Form des Glen'schen Gesetzes $\dot{\epsilon}=\dot{\epsilon}_{0} \tau^{n} \exp (k \theta)$ wurde benützt, um die Profile der Horizontalund der Vertikalgeschwindigkeiten und von diesen die Temperatur- und Altersprofile zu berechnen. Es wird gezeigt, dass durch Substitution von $\theta$ durch eine linear mit der Höhe ansteigende Funktion Geschwindigkeitsprofile für alle Eiskappen erhalten werden, welche die wahren Verhältnisse ausgezeichnet approximieren. Über einer kritischen Höhe $h_{\mathrm{c}}$, wo die Abweichung von der Linearität gross wird, ist der Einfluss der Temperatur auf das Fliessen des Eises schon vernachlässigbar klein. Beim Vergleich der beschriebenen Theorie mit derjenigen von Robin (1955) erhält man Temperaturdifferenzen $\Delta T$, die bis zu $30 \%$ grösser sind. Ausserdem ergibt die jetzige Theorie Eisalter, welche gegenüber denjenigen des NyeModells erheblich höher liegen; z.B. ergibt sich für eine relative Höhe über dem Felsboden von $h / H=0 \cdot{ }_{\mathrm{I}}$ ein um mehr als $50 \%$ höheres Eisalter.
\end{abstract}

\section{Introduction}

Concerning the movement of large ice sheets, two limiting cases have been calculated, pure gliding over the bedrock (Nye, 1952) and the behaviour of the ice like a Newtonian liquid (Philberth, r956). These can both be considered special cases of Glen's law, with the exponent $n=\infty$ and $n=\mathrm{I}$ respectively. As has been shown by Haefeli (I96r[a], [b]) and by Philberth and Federer (I970), an excellent agreement with the real surface profile of the Greenland ice sheet is obtained if the exponent is taken as $n=3 \cdot 5$.

The temperature profile depends on the horizontal and the vertical velocity profiles (Robin, I955). These velocities are functions of the shear strain-rate, which is itself a function of the shear stress and the temperature. An exact calculation of the mutual dependence of temperature and velocity profiles would lead to very complicated expressions. Therefore one has to rely on simplified models. In the following we shall present such a model, which is sufficiently accurate and relatively simple.

Since the fundamental calculation of the temperature profile by Robin (1955), a number of different refinements have been published (Weertman, I961, I968; Lliboutry, I968). But so far the significance of the vertical velocity for the temperature profile has not been taken into account sufficiently. Generally one still uses the simplified assumption that the vertical velocity decreases in proportion to the distance from the bedrock. This assumption leads to a rather imprecise temperature profile. In a recent paper by Dansgaard and Johnsen

* Permanent address: D 803i Puchheim, Peter Rosseggerstr. 6, Germany. 
( $1969[\mathrm{~b}]$ ) the vertical velocity $v_{h}$ has been calculated from a simplified $v_{x}$-profile by use of the continuity equation for incompressible media. The simplification consists in the assumption, that $v_{x}$ increases linearly up to a certain height from the bedrock and then remains constant up to the surface. If this height is chosen correctly, the derived $v_{h}$ is a good approximation to the true $v_{h}$. It is difficult, however, to determine the value of this height, if the $v_{x}$-profile is not known from measurement or from the theory. Dansgaard and Johnsen (1969[a]) also calculate the temperature profile with their improved function for $v_{h}$, and obtain good agreement with measurement. In the vicinity of the bedrock the vertical temperature gradient is approximately given by the sum of geothermal heat and the heat of friction, divided by the thermal conductivity of the ice (Nye, r95 1 ; Lliboutry, r968). Above this lower region the temperature profile has a monotonic curvature. The curvature lies in the region where the conflict between heat conduction from the lower parts and transport of cold ice from above is most pronounced, i.e. where the product of height $h$ above the bedrock and vertical velocity $v_{h}$ of the ice has an absolute value of the order of the diffusivity $\kappa$ of the ice (cf. Appendix A). The vertical velocity $v_{h}$ in this region has a large influence on the temperature profile. Thus the calculations in this paper aim at a more accurate estimate of the vertical velocity in this region.

\section{Symbols Used in this PAper}

\begin{tabular}{|c|c|c|}
\hline Symbol & Units & Description \\
\hline$x$ & $\mathrm{~km}$ & Horizontal coordinate, distance from ice divide. \\
\hline$h$ & $\mathrm{~m}$ & Vertical coordinate, height above bedrock. \\
\hline$A$ & $\mathrm{~m} \mathrm{a}^{-1}$ & Long-time average of total accumulation (in ice thickness). \\
\hline$-A$ & $\mathrm{~m} \mathrm{a}^{-1}$ & Vertical downward velocity, measured from the surface. \\
\hline$v_{x}$ & $\mathrm{~m} \mathrm{a}^{-1}$ & Horizontal velocity. \\
\hline$v_{x \mathrm{~m}}$ & $\mathrm{~m} \mathrm{a}^{-1}$ & Mean horizontal velocity. \\
\hline$v_{h}$ & $\mathrm{~m} \mathrm{a}^{-1}$ & Vertical velocity. \\
\hline$-v_{H}$ & $\mathrm{~m} \mathrm{a}^{-1}$ & $\begin{array}{l}\text { Vertical downward velocity in the immediate vicinity of the } \\
\text { surface for a profile which moves with } v_{x \mathrm{~m}} \text {. }\end{array}$ \\
\hline$y=k G(H-h)$ & & Running dimensionless depth parameter. \\
\hline$r=k G H$ & & Full dimensionless depth parameter. \\
\hline $\begin{array}{l}H \\
H_{0}\end{array}$ & $\mathrm{~m}$ & Total height of ice sheet, $H=H(x)$. \\
\hline$H_{0}$ & $\mathrm{~m}$ & Standard total height $(2500 \mathrm{~m})$ \\
\hline$h_{\mathrm{c}}$ & $\mathrm{m}$ & $\begin{array}{l}\text { Critical height, where curvature of temperature profile has its } \\
\text { maximum. }\end{array}$ \\
\hline$\sigma_{x}-\sigma_{y}$ & bar & Longitudinal stress. \\
\hline$\tau, \tau_{x h}$ & bar & Shear stresses. \\
\hline $\begin{array}{l}\dot{\epsilon}, \dot{\epsilon}_{0} \\
\mathrm{e}\end{array}$ & $a^{-1}$ & $\begin{array}{l}\text { Shear strain-rates. } \\
\text { Base of natural logarithm. }\end{array}$ \\
\hline$g$ & $\mathrm{~m} \mathrm{~s}^{-2}$ & $\begin{array}{l}\text { Base of natural logaritnm. } \\
\text { Acceleration due to gravity. }\end{array}$ \\
\hline$\rho$ & $\mathrm{Mg} \mathrm{m}^{-3}$ & Density of ice. \\
\hline$G$ & $\operatorname{deg} m^{-1}$ & Real thermal gradient near the bottom. \\
\hline$G_{0}$ & $\operatorname{deg} \mathrm{m}^{-1}$ & Standard value of $G\left(\mathrm{I} / 44 \mathrm{deg} \mathrm{m}^{-1}\right)$. \\
\hline$G_{\mathrm{g}}$ & $\operatorname{deg} \mathrm{m}^{-1}$ & Geothermal gradient. \\
\hline $\begin{array}{l}G_{\mathrm{f}} \\
n\end{array}$ & $\operatorname{deg} \mathrm{m}^{-1}$ & $\begin{array}{l}\text { Thermal gradient due to heat generation in shear layer. } \\
\text { Stress exponent. }\end{array}$ \\
\hline$\kappa$ & $m^{2} a^{-1}$ & Thermal diffusivity of ice $\left(3^{8} \mathrm{~m}^{2} \mathrm{a}^{-1}\right)$ \\
\hline$t$ & a & Age of the ice. \\
\hline$p_{\mathrm{s}}$ & bar & Hydrostatic pressure. \\
\hline$Q^{\star}$ & $\mathrm{J} \mathrm{mol}^{-1}$ & Activation energy of creep. \\
\hline
\end{tabular}




$\begin{array}{lll}\text { Symbol } & \text { Units } & \text { Description } \\ R & \mathrm{~J} \mathrm{~mol}^{-1} \mathrm{deg}^{-1} & \text { Universal gas content. } \\ k & \mathrm{deg}^{-1} & \text { Temperature coefficient. }\left(0 . \mathrm{I}-0.25 \mathrm{deg}^{-1}\right) . \\ T & \mathrm{~K} & \text { Temperature. } \\ T_{\mathrm{B}} & \mathrm{K} & \text { Temperature at the bottom. } \\ \Delta \mathrm{T} & \mathrm{deg} & \begin{array}{l}\text { Real temperature difference between bedrock and a point } \\ \text { vertically above. }\end{array} \\ \Delta \mathrm{T}_{0} & \mathrm{deg} & \text { Temperature difference as read from Table I. } \\ S & \mathrm{~K} & \text { Pressure melting point. } \\ \theta & \mathrm{deg} & \begin{array}{l}\text { Difference between actual temperature and pressure melting } \\ \text { point. }\end{array} \\ \alpha & \circ & \text { Surface slope relative to horizontal plane. } \\ \beta & \circ & \text { Slope of bedrock relative to horizontal plane. } \\ \phi(y, Y) & & \text { Profile function for horizontal flow. } \\ \psi(y, Y) & & \text { Profile function for vertical flow. }\end{array}$

\section{Assumptions}

(I) The surface slope $\alpha$ and its horizontal gradient $\partial \alpha / \partial x$ are small.

(2) The bedrock is horizontal $(\beta=0)$.

(3) The ice sheet does not glide over the bedrock $\left(v_{x}=0\right.$ at $\left.h=0\right)$.

(4) The density $\rho$ is constant throughout the ice sheet.

(5) $\partial T / \partial x$ and $\partial G / \partial x$ are very small.

(6) The horizontal gradient of the longitudinal stress $\frac{\mathrm{I}}{2} \frac{\partial\left(\sigma_{x}-\sigma_{y}\right)}{\partial x}$ is very small.

(7) The horizontal gradient of the accumulation $\partial A / \partial x$ is small.

(8) Only the two-dimensional case is considered.

(9) All the values are stationary.

Assumption (2) is made to simplify the calculations, although these will be approximately valid for small $\beta$ and very small $\partial \beta / \partial x$. If $\beta \neq 0$ the $x$-coordinate is parallel and the $h$ coordinate orthogonal to the bedrock. For the case of a circular ice sheet the same values for $v_{h}, \partial T / \partial h, T$ and $t$ are obtained if the linear distance $x$ is changed into the radial distance $r$.

The validity of assumption (6) is a matter of discussion in the vicinity of the ice divide, and also in the outer regions of ice sheets where ice flows (Haefeli, I968) and other types of spatial instabilities (Lliboutry, I968) may occur.

\section{Calculations}

We start from the generalized Glen's law (Weertman, I968):

$$
\dot{\epsilon}=\dot{\epsilon}_{0} \tau^{n} \exp \left(-Q^{\star} / R T\right) \text {. }
$$

In the region of interest the temperature interval and the gradient of the pressure melting point are relatively small, so we can use (Budd, I968; Lliboutry, I968):

$$
\dot{\epsilon}=\dot{\epsilon}_{0} \tau^{n} \exp \{k(T-S)\} \text {. }
$$

Now for $\mathcal{T}$ in equation (I) we use the linear expression

$$
\tau=-h G+T_{\mathrm{B}} \text {. }
$$

The pressure melting point depends on $H-h$. This dependence being very small, however, we shall neglect it, so that $S$ depends only on $x$. For the factor $G$ we put numerically the geothermal gradient $G_{\mathrm{g}}$ or, for the case of an additional heat of friction, $G_{\mathrm{g}}+G_{\mathrm{f}}$. If heat of friction is present the linear form (2) differs slightly from the true temperature profile in the immediate vicinity of the bedrock, because the heat of friction is not formed at the interface 
between bedrock and ice, but in the lowermost layers; the deviation from the linear profile, however, is small (Lliboutry, I968).

Above a certain height $h_{\mathrm{c}}$ the linear form (2) ceases to be a valid description of the true temperature profile. Nevertheless we can use Equation (2) for a rather precise calculation of $v_{x}$ and $v_{h}$ in the whole range of $h$. This is proved in Appendix A.

Using assumption (6) and Equation (BI) (see Appendix B) one obtains, upon integration

$$
\tau_{x h}=\rho g \sin \alpha(H-h) .
$$

As shown in Appendix B, Equation (3) can be inserted into Equation (I) which becomes

$$
\partial v_{x} / \partial h=\dot{\epsilon}_{0}(\rho g \sin \alpha)^{n} \exp \left\{k\left(T_{\mathrm{B}}-S\right)\right\}(H-h)^{n} \exp (-k G h) .
$$

In the following, the movement of the ice will not be calculated from the slope $\alpha$ but by means of the mass budget. The first three factors of Equation (4) are merely a function $f(x)$ which is of no further interest. With $n=3$ Equation (4) becomes:

$$
\partial v_{x} / \partial h=f(x)(H-h)^{3} \exp (-k G h) .
$$

Upon substitution of $Y=k G H$ and $y=k G(H-h)$, integration of Equation (5) gives

$$
v_{x}=\int_{0}^{x} A \mathrm{~d} x H^{-1} \phi(y, r)=v_{x \mathrm{~m}} \phi(y, r),
$$

where $v_{x m}$ is the mean value of $v_{x}$ and

$$
\begin{aligned}
\phi(y, r) & =Y\left[-C_{\mathrm{I}} \exp (y-r)\left(y^{3}-3 y^{2}+6 y-6\right)+C_{2}\right], \\
C_{\mathrm{I}} & =\left(Y^{4}-4 Y^{3}+\mathrm{I}_{2} Y^{2}-24 Y+24-24 / \mathrm{e}^{Y}\right)^{-1}, \\
C_{2} & =C_{\mathrm{I}}\left(Y^{3}-3 Y^{2}+6 Y-6\right) .
\end{aligned}
$$

with

and

Differentiation of Equation (6) with respect to $x$ yields:

$$
\frac{\partial v_{x}}{\partial x}=\phi \frac{\partial v_{x \mathrm{~m}}}{\partial x}+v_{x \mathrm{~m}} \frac{\partial \phi}{\partial x}
$$

or

$$
\frac{\partial v_{x}}{\partial x}=\phi A H^{-1}-v_{x \mathrm{~m}} \frac{\partial H}{\partial x}\left(\frac{\phi}{H}-\frac{\partial \phi}{\partial H}\right) .
$$

The third term in Equation (7) is smaller than the second term for all values of $y, Y$ and $x$, but in the central region both terms are small compared with the first one. In many cases, especially if $H>2$ ooo $\mathrm{m}$, the $\partial \phi / \partial H$ term is only a small (positive) correction to the $\phi / H$ term so that we shall neglect it in further calculations.

Equation (7) now reads

$$
\frac{\partial v_{x}}{\partial x}=\left(A-v_{x \mathrm{~m}} \frac{\partial H}{\partial x}\right) \frac{\phi}{H}
$$

We define

$$
-v_{H}=A-v_{x \mathrm{~m}} \frac{\partial H}{\partial x}
$$

or:

$$
-v_{H} \approx A\left(\mathrm{I}-\frac{x}{H} \frac{\partial H}{\partial x}\right)
$$

where $v_{x \mathrm{~m}} \partial H / \partial x$ is the change of ice thickness per unit time considered for a profile which moves with the mean horizontal velocity $v_{x \mathrm{~m}}$, and $-v_{H}$ is the vertical downward velocity of ice particles in the immediate vicinity of the surface considered for a profile which moves with the mean horizontal velocity $v_{x \mathrm{~m}} .-v_{H}$ is measured from a horizontal plane and in the case of $\beta \neq 0$ from a plane parallel to the bedrock. 
Under normal conditions $-v_{x \mathrm{~m}} \partial H / \partial x$ increases a little more than linearly with $x$, while $A$ can be assumed to be almost independent of $x$. Therefore $v_{H}$ is nearly constant as long as $A$ in Equation (9) is the predominant term, i.e., according to Equation (9a), as long as

$$
x \ll \frac{H}{|\partial H / \partial x|} .
$$

Because of assumption (4) the continuity equation can be written

$$
\operatorname{div} \mathbf{v}=0, \quad \partial v_{x} / \partial x=-\partial v_{h} / \partial h .
$$

Integration of Equation (8) and using Equation (9) yields:

where

$$
v_{h}=v_{H} \psi(y, Y)
$$

$$
\psi(y, r)=C_{1} \mathrm{e}^{y-r}\left(y^{3}-6 y^{2}+\mathrm{I} 8 y-24\right)-C_{2} y+24 C_{\mathrm{I}} / \mathrm{e}^{r}+\mathrm{I} .
$$

The equation of stationary heat transport reads:

$$
\nabla^{2} T=\frac{\mathrm{I}}{\kappa} \mathbf{v} \operatorname{grad} T .
$$

Under the condition (Io) and with assumption (5), $\frac{\partial T}{\partial x}$ and $\frac{\partial^{2} T}{\partial x^{2}}$ can be neglected. On the E.G.I.G. profile in Greenland, for example, the gradient $\partial T_{\mathrm{B}} / \partial x$ is very small (Philberth and Federer, 1970). Equation (12) now reads:

which yields, upon integration,

$$
\frac{\partial^{2} T}{\partial h^{2}}=\frac{v_{h}}{\kappa} \frac{\partial T}{\partial h},
$$

$$
\frac{\partial T}{\partial h}=-G \exp \left[\frac{\left|v_{H} H\right|}{\kappa} \frac{C_{\mathrm{I}}}{\Upsilon}\left\{\mathrm{e}^{y-Y}\left(y^{3}-9 y^{2}+36 y-60\right)-\frac{C_{2} y^{2}}{2 C_{\mathrm{I}}}+\frac{24 y}{\mathrm{e}^{X}}+\frac{y}{C_{\mathrm{I}}}-C_{3}\right\}\right]
$$

where

$$
C_{3}=Y^{3}-9 Y^{2}+36 Y-60-C_{2} Y^{2} / 2 C_{1}+24 Y / \mathrm{e}^{r}+Y / C_{1} .
$$

From Equation (13) the temperatures at all heights are obtained by integration;

$$
T(h)=T_{\mathrm{B}}+\int_{0}^{h} \frac{\partial T}{\partial h} \mathrm{~d} h, \quad T_{\mathrm{B}}=T_{H}-\int_{0}^{H} \frac{\partial T}{\partial h} \mathrm{~d} h .
$$

The age $t$ of the ice at any height can be calculated by means of the vertical velocity relative to the surface, i.e. $-A \psi(y, Y)$ (see Equation (I I )).

$$
t=\int_{H}^{h} \frac{\mathrm{I}}{-A \psi(y, Y)} \mathrm{d} h=\frac{H}{A} \int_{\mathrm{I}}^{h / H} \frac{\mathrm{d}(h / H)}{-\psi\{Y(\mathrm{I}-h / H), r\}} .
$$

The integrals in Equations ( $\mathrm{I}_{4}$ ) and ( $\mathrm{I}_{5}$ ) do not have exact solutions (see also Robin, I955). The values for $T(h)$ and for the age $t$ were therefore calculated on the digital computer CDG 1604 of the Rechenzentrum der E.T.H., Zürich.

\section{Results}

The values calculated with Equations (13) and (15) are shown in Tables I and II. In order to obtain the maximum information from Table $I$ the product $\Delta T_{0}=\frac{\Delta T G_{0} H_{0}}{G H}$ is given for 7 values of $Y=k G H$ as a function of the relative heights $h / H$ for thin $\left(\left|v_{H} H\right|=75 \mathrm{~m}^{2} \mathrm{a}^{-1}\right)$, medium $\left(\left|\mathrm{v}_{H} H\right|=375\right.$ and $\left.75^{\circ} \mathrm{m}^{2} \mathrm{a}^{-1}\right)$ and thick $\left(\left|v_{H} H\right|=\right.$ 
I $\left.500 \mathrm{~m}^{2} \mathrm{a}^{-1}\right)$ ice sheets. $\Delta T$ is the difference between the temperatures at the bedrock and the height $h / H, G_{0}$ is the standard thermal gradient taken as $\mathrm{r} / 44 \mathrm{deg} \mathrm{m}^{-\mathrm{I}}$ and $H_{0}=2500 \mathrm{~m}$. In order to find $\Delta T$ for any thermal gradient $G$ at the bedrock and any total height $H$ of a particular point on an ice sheet, the value of $\Delta T_{0}$, which is read from the appropriate Table, has to be multiplied by $44 \mathrm{GH} / 25^{00} \mathrm{deg}^{-1}$, so that

$$
\Delta T=\Delta T_{0}\left(G H \mathrm{r} .76 \times \mathrm{ro}^{-2} \mathrm{deg}^{-1}\right) .
$$

Values of $\left|v_{H} H\right|$ which are between those given in Table I, a-d, are best interpolated graphically, where one has to note that, by Equation (13), for $\left|v_{H} H\right|=0, \Delta T=G h$ and for $v_{H} H=\infty: \Delta T=0$. Column (I) for $Y=\infty$ gives the temperature profile of Robin (i955), while column (7) for $Y=$ o represents the temperature profile obtained by Glen's law $\dot{\epsilon}=$ const. $\tau^{3}$.

Table I. Temperature differences $\mathrm{T}_{0}$ IN Degrees Between Bedrock and the relative height $h / H$,

(a) $\left|v_{H} \cdot H\right|=75 \mathrm{~m}^{2} \mathrm{a}^{-1}$

\begin{tabular}{|c|c|c|c|c|c|c|c|}
\hline & (I) & (2) & $\begin{array}{l}\text { (3) } \\
14.2\end{array}$ & (4) & (5) & $\begin{array}{c}(6) \\
0.83\end{array}$ & (7) \\
\hline & $4^{2.6}$ & 4 & 43.8 & $44 \cdot 4$ & & $45 \cdot 9$ & $\begin{array}{c}0 \\
46.2\end{array}$ \\
\hline 0.95 & $4^{1.5}$ & & & & 43.7 & & 40.2 \\
\hline & & $4^{1}$. & & & 4 & 2 & 43 \\
\hline 85 & 38.6 & 39.6 & 0.0 & 40.4 & 40.9 & & \\
\hline 8 & 37.5 & $3^{8.1}$ & 8.5 & 38.8 & $39 \cdot 3$ & 40.0 & 40 \\
\hline 75 & 3 & 36.4 & 36.8 & $37 \cdot 1$ & 3 & $3^{8.1}$ & 38 \\
\hline & & 34.7 & 5.0 & 35 & 7 & $3^{6.2}$ & 37.4 \\
\hline 0.65 & & 32. & 33. & 3 & 33.7 & 34.2 & \\
\hline 6.6 & & 30.6 & & & $3^{\text {I.6 }}$ & & \\
\hline & & 2 & 29 & & 29.4 & 7 & $2 !$ \\
\hline & & 2 & 6.7 & 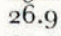 & & 27 & 27. \\
\hline 45 & .0 & 2. & $4 \cdot$ & 24.5 & 24 & & 24 . \\
\hline & 6 & 2 & . & 2 & $22 . \mathrm{I}$ & .2 & 22. \\
\hline 0.35 & IO. 1 & 19.3 & 19.4 & If & & & I 9.6 \\
\hline & & & I6. & I & I 6.8 & 9 & 16. \\
\hline 25 & I & 14. & 4. & & I4. I & 4. I & 14.1 \\
\hline & & II. & II & II & II. 3 & I. & II. \\
\hline & 8.5 & 8. & 8. & 8 & 8 & 8 & 8 \\
\hline & & & & & & & \\
\hline 0.0 & & & & & & & \\
\hline & & & & & & & \\
\hline
\end{tabular}

(c) $\left|v_{H} \cdot H\right|=750 \mathrm{~m}^{2} \mathrm{a}^{-1}$

\begin{tabular}{|c|c|c|c|c|c|c|c|}
\hline & (I) & (2) & (3) & (4) & (5) & (6) & (7) \\
\hline h/H & $r=\infty$ & 25 & 14.2 & 8.5 & & 0.83 & 0 \\
\hline & I6.I & 17.6 & 18.3 & 19.2 & 20.0 & 21.8 & 22.3 \\
\hline 95 & 16.1 & 17.6 & 18.3 & 19.2 & 20.0 & 21.8 & 22.3 \\
\hline & It & 17. & & 19.2 & 20.0 & 2 & 22.3 \\
\hline 85 & 16.1 & 17.6 & 18.3 & 19.2 & 20.0 & $2 \mathrm{I} .8$ & 22.3 \\
\hline 8 & 16. & 17.6 & 18.3 & 19.2 & 20.0 & 21.7 & 22.2 \\
\hline 75 & I6.I & 17.6 & 18. & 19.2 & 20.0 & 21.7 & 22.2 \\
\hline & 6 & 17.5 & 18.3 & I9. I & I9.9 & 2 I . 6 & 22.1 \\
\hline 65 & 16.0 & 17.5 & 18 & I9. I & 19.9 & 21.5 & 22.0 \\
\hline 6 & 16.0 & 17.4 & 18.1 & 18.9 & 19.7 & $2 \mathrm{I} \cdot 3$ & 21.8 \\
\hline 55 & I5.9 & 17.3 & & 8.7 & I9. & 21.0 & 21.4 \\
\hline .5 & & I 7 & $I^{\prime}$ & 18.4 & I9.I & 20.5 & 20.9 \\
\hline 45 & 15.4 & I6.6 & & 17.9 & 18.5 & $9 \cdot 7$ & 0.0 \\
\hline 0.4 & 14. & 16.0 & & 17.2 & 17. & 7 & I8.9 \\
\hline 0.35 & 14.2 & 15.2 & I 5.6 & I6. I & 16.5 & 17.3 & 17.4 \\
\hline 3 & 13.2 & 14.0 & 14.3 & 14.7 & I 5.0 & ${ }^{1} 5.6$ & 15. \\
\hline .2 & II 1.8 & 12.4 & 12 & I 2. & I3.I & $3 \cdot 4$ & I 3.5 \\
\hline 0.22 & IO & 10. & ro. & 10.8 & го. 9 & II. 0 & I I. 0 \\
\hline 0.1 & 8.0 & 8.2 & 8. & 8.3 & 8. & 8.4 & 8. \\
\hline & 5. & & & & & 5. & $5 \cdot 7$ \\
\hline & & & & 2. & 2. & 2. & \\
\hline & & 0 & & & & & \\
\hline
\end{tabular}

(b) $\left|v_{H} \cdot H\right|=375 \mathrm{~m}^{2} \mathrm{a}^{-1}$

$\begin{array}{ccccccc}(\mathrm{I}) & (2) & (3) & (4) & (5) & (6) & (7) \\ \infty & 25 & \mathrm{I} 4.2 & 8.53 & 5 & 0.83 & 0 \\ 22.7 & 24.1 & 24.8 & 25.7 & 26.6 & 28.4 & 28.9 \\ 22.7 & 24.1 & 24.8 & 25.7 & 26.5 & 28.3 & 28.8 \\ 22.6 & 24.0 & 24.8 & 25.6 & 26.4 & 28.2 & 28.7 \\ 22.6 & 23.9 & 24.7 & 25.5 & 26.3 & 28.1 & 28.6 \\ 22.5 & 23.8 & 24.5 & 25.4 & 26.2 & 27.9 & 28.4 \\ 22.3 & 23.7 & 24.4 & 25.2 & 25.9 & 27.6 & 28.0 \\ 22.1 & 23.4 & 24.1 & 24.9 & 25.6 & 27.2 & 27.6 \\ 21.8 & 23.1 & 23.6 & 24.4 & 25.2 & 26.6 & 27.0 \\ 21.4 & 22.6 & 23.2 & 23.9 & 24.5 & 25.8 & 26.2 \\ 20.9 & 21.9 & 22.5 & 23.1 & 23.8 & 24.9 & 25.2 \\ 20.1 & 21.1 & 21.6 & 22.2 & 22.7 & 23.7 & 23.9 \\ 19.1 & 20.1 & 20.5 & 21.0 & 21.4 & 22.2 & 22.4 \\ 18.0 & 18.8 & 19.1 & 19.5 & 19.9 & 20.5 & 20.6 \\ 16.5 & 17.2 & 17.5 & 17.8 & 18.0 & 18.5 & 18.6 \\ 14.9 & 15.4 & 15.6 & 15.8 & 15.9 & 16.2 & 16.3 \\ 12.9 & 13.2 & 13.4 & 13.5 & 13.6 & 13.8 & 13.8 \\ 10.7 & 10.9 & 11.0 & 11.1 & 11.1 & 11.2 & 11.2 \\ 8.2 & 8.3 & 8.4 & 8.4 & 8.4 & 8.5 & 8.5 \\ 5.6 & 5.6 & 5.6 & 5.7 & 5.7 & 5.7 & 5.7 \\ 2.8 & 2.8 & 2.8 & 2.8 & 2.8 & 2.8 & 2.8 \\ 0 & 0 & 0 & 0 & 0 & 0 & 0\end{array}$

(d) $\left|v_{H} \cdot H\right|=\mathrm{I} 500 \mathrm{~m}^{2} \mathrm{a}^{-1}$

$\begin{array}{lcccccc}(1) & (2) & (3) & (4) & (5) & (6) & (7) \\ 0 & 25 & 14.2 & 8.5 & 5 & 0.83 & 0 \\ 11.4 & 12.9 & 13.6 & 14.4 & 15.2 & 16.8 & 17.3 \\ 11.4 & 12.9 & 13.6 & 14.4 & 15.2 & 16.8 & 17.3 \\ 11.4 & 12.9 & 13.6 & 14.4 & 15.2 & 16.8 & 17.3 \\ 11.4 & 12.9 & 13.6 & 14.4 & 15.2 & 16.8 & 17.3 \\ 11.4 & 12.9 & 13.6 & 14.4 & 15.2 & 16.8 & 17.3 \\ 11.4 & 12.9 & 13.6 & 14.4 & 15.2 & 16.8 & 17.2 \\ 11.4 & 12.9 & 13.6 & 14.4 & 15.2 & 16.8 & 17.2 \\ 11.4 & 12.9 & 13.6 & 14.4 & 15.2 & 16.8 & 17.2 \\ 11.4 & 12.9 & 13.6 & 14.4 & 15.2 & 16.8 & 17.2 \\ 11.4 & 12.9 & 13.6 & 14.4 & 15.2 & 16.7 & 17.2 \\ 11.4 & 12.9 & 13.6 & 14.4 & 15.1 & 16.6 & 17.1 \\ 11.4 & 12.8 & 13.5 & 14.3 & 15.0 & 16.4 & 16.8 \\ 11.3 & 12.7 & 13.4 & 14.1 & 14.8 & 16.0 & 16.4 \\ 11.1 & 12.4 & 13.0 & 13.7 & 14.3 & 15.3 & 15.6 \\ 10.7 & 11.9 & 12.4 & 13.0 & 13.4 & 14.2 & 14.4 \\ 10.1 & 11.1 & 11.5 & 11.8 & 12.2 & 12.7 & 12.8 \\ 9.0 & 9.7 & 10.0 & 10.2 & 10.4 & 10.7 & 10.7 \\ 7.5 & 7.9 & 8.0 & 8.1 & 8.2 & 8.3 & 8.3 \\ 5.3 & 5.5 & 5.6 & 5.6 & 5.6 & 5.6 & 5.6 \\ 2.8 & 2.8 & 2.8 & 2.8 & 2.8 & 2.8 & 2.8 \\ 0 & 0 & 0 & 0 & 0 & 0 & 0\end{array}$


Table II. Age of ice in years as a function of relative height $h / H$. The values refer to $H / A=2500$ a

\begin{tabular}{|c|c|c|c|c|c|c|c|}
\hline$h / H$ & $r \stackrel{(\mathrm{I})}{=} \infty$ & $\begin{array}{l}\text { (2) } \\
25\end{array}$ & $\begin{array}{l}\text { (3) } \\
\mathrm{I} 4.2\end{array}$ & $\begin{array}{l}\text { (4) } \\
8.5\end{array}$ & $\begin{array}{c}(5) \\
5\end{array}$ & $\begin{array}{c}(6) \\
0.83\end{array}$ & $r \stackrel{(7)}{=} 0$ \\
\hline I & o & o & o & o & o & o & o \\
\hline 0.95 & I 28 & I 28 & I 28 & 129 & 129 & 129 & 129 \\
\hline 0.9 & 263 & 264 & 264 & 265 & 265 & 266 & 267 \\
\hline 0.85 & 406 & 408 & 408 & 409 & 411 & $4^{1} 4$ & $4^{15}$ \\
\hline 0.8 & $55^{8}$ & 560 & 562 & $5^{64}$ & $5^{67}$ & 573 & 575 \\
\hline 0.75 & 719 & 723 & 726 & 730 & 734 & 745 & 749 \\
\hline 0.7 & 892 & 898 & 903 & 908 & $9^{1} 5$ & 933 & $94^{\circ}$ \\
\hline 0.65 & I 080 & I 090 & I 094 & 1102 & 1112 & I $14^{\circ}$ & I $15^{\circ}$ \\
\hline 0.6 & I 280 & I $29^{\circ}$ & I 300 & $13^{1} 3$ & 1330 & 1370 & I 380 \\
\hline 0.55 & I 500 & I 520 & I 530 & I 546 & I 569 & I 630 & $165^{\circ}$ \\
\hline 0.5 & I 730 & I 760 & 1 780 & 1810 & I 840 & I 920 & I 954 \\
\hline 0.45 & 2000 & 2040 & 2060 & 2100 & 2140 & 2260 & 2310 \\
\hline 0.4 & 2290 & $235^{\circ}$ & $23^{80}$ & 2430 & 2500 & 2670 & $273^{\circ}$ \\
\hline 0.35 & 2630 & 2700 & 2760 & 2820 & 2910 & 3160 & $325^{\circ}$ \\
\hline 0.3 & 3010 & 3120 & 3200 & 3300 & 3430 & 3780 & 3900 \\
\hline 0.25 & $347^{\circ}$ & 3620 & $374^{\circ}$ & 3890 & 4080 & 4600 & 4780 \\
\hline 0.2 & 4030 & 4260 & $444^{\circ}$ & 4670 & $497^{\circ}$ & $575^{\circ}$ & 6030 \\
\hline 0.15 & 4760 & 5140 & $543^{\circ}$ & $58 \mathrm{IO}$ & 6300 & 7560 & 8 oro \\
\hline O.I & 5780 & 6500 & 7060 & 7780 & 8670 & 10960 & I $177^{\circ}$ \\
\hline 0.05 & $755^{\circ}$ & 9500 & I0 $95^{\circ}$ & I $277^{\circ}$ & 14960 & $2053^{\circ}$ & 22500 \\
\hline 0.01 & I I 890 & 25900 & 35200 & $4^{6} 300$ & 59400 & $9^{2} 400$ & 104100 \\
\hline
\end{tabular}

\section{Example I}

If we take Station Jarl Joset, Greenland, where $H=2500 \mathrm{~m},\left|v_{H}\right|=0.3 \mathrm{~m}$ of ice a ${ }^{-1}$,

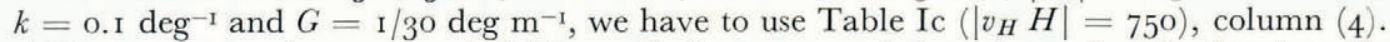
$\Delta T_{0}$ at $\mathrm{I} 500 \mathrm{~m}$ above ground $(h / H=0.6)$, i.e. I $000 \mathrm{~m}$ below the surface is $\mathrm{r} 8.9 \mathrm{deg}$. So the real $\Delta \mathcal{T}$ becomes

$$
\Delta T=18.9 \times 1 / 30 \times 2500 \times 1.76 \times 10^{-2}=27.8 \mathrm{deg} .
$$

At a height of I $500 \mathrm{~m}$ above the bedrock, i.e. at a depth of I $000 \mathrm{~m}$, a temperature of $-30.0^{\circ} \mathrm{C}$ has been measured (Philberth, 1970). Therefore the bottom temperature at Station Jarl-Joset is $-30.0+27.8=-2.2^{\circ} \mathrm{C}$, which is slightly below the pressure melting point.

\section{Example 2}

At the ice divide (Crête) in Greenland $H=3000 \mathrm{~m},\left|v_{H}\right|=0.25 \mathrm{~m}$ of ice $\mathrm{a}^{-1}$, $G=\mathrm{I} / 44 \mathrm{deg} / \mathrm{m}$ and $k=0.15 \mathrm{deg}^{-1}$.

Table Ic gives for $h / H=\mathrm{I}$ and $Y=\mathrm{I} 0.2$ an interpolated value of $\Delta T_{0}=\mathrm{I} 8.7 \mathrm{deg}$, so that, according to Equation (I6):

$$
\Delta T=22.4 \mathrm{deg},
$$

which is the temperature difference between the bedrock and the surface. In comparison, Robin's (1955) paper gives $\Delta T=19.4 \mathrm{deg}$.

\section{Example 3}

According to Haefeli ( $\left.\mathrm{I}^{6} \mathrm{r}[\mathrm{b}]\right)$ the center of the Jungfraujoch Eiskalotte has the following

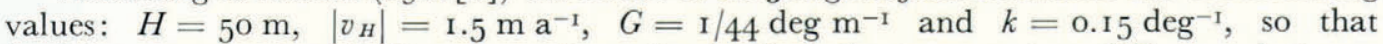
$\left|v_{H} H\right|=75 \mathrm{~m}^{2} \mathrm{a}^{-1}$ and $Y=0.17$. In order to find the temperature difference between bedrock and surface we use Table Ia, column (7) which yields $\Delta T_{0}=46.2 \mathrm{deg}$ and $\Delta T=0.93 \mathrm{deg}$ for the temperature difference over the whole thickness.

\section{Example 4}

In order to obtain the age at $h / H=$ o.I for a station with $k=0.1 \operatorname{deg}^{-1}, G=\mathrm{I} / 50 \mathrm{deg}$ $\mathrm{m}^{-1}, H=400 \mathrm{~m}$ and $A=0.6 \mathrm{~m}$ of ice $\mathrm{a}^{-1}$ we have to use column (6) of Table II which 
yields ro 960 a. This is the value for $H / A=2500$ a. For the present values, i.e. for $H / A=400 / 0.6$ a the age is

$$
t=\frac{\text { Io } 960 \times 400 \times \mathrm{I}}{0.6 \times 2500}=2920 \text { years } 40 \mathrm{~m} \text { above the bedrock. }
$$

With Nye's model (column (I)), an age of I 540 years would be obtained.

\section{Example 5}

According to Hansen and Langway (I966), the temperature difference between the bedrock and the surface at Camp Century is $\Delta T=\mathrm{II} .0 \mathrm{deg}$. Let us compare this value with the one given by the present theory.

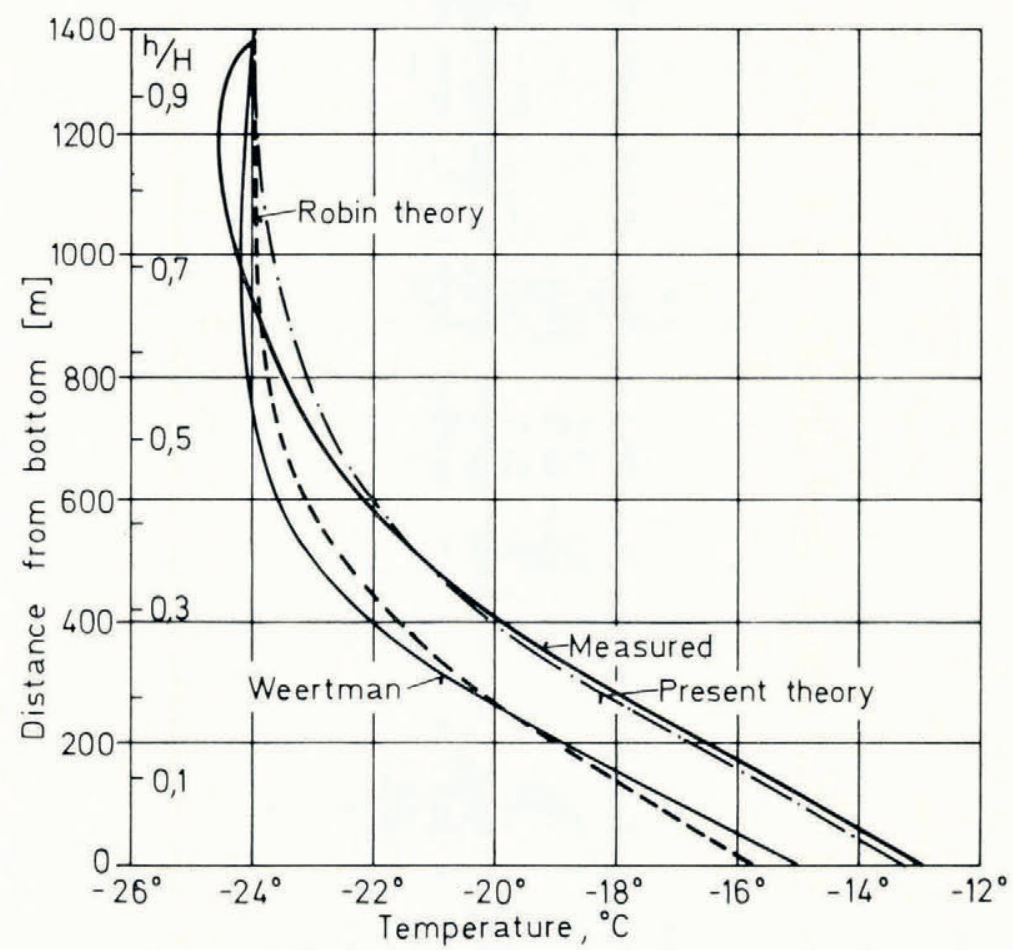

Fig. I. Measured (by B. L. Hansen) and theoretical temperature profiles for the Camp Century bore hole.

According to Weertman (I g68), $H=\mathrm{I} 400 \mathrm{~m}, k=0 . \mathrm{I} \mathrm{deg}{ }^{-1}, G=\mathrm{I} / 56 \mathrm{deg} \mathrm{m}^{-1}$ and $\left|v_{H}\right|=0.36 \mathrm{~m} \mathrm{a}^{-1}$; thus $\left|v_{H} H\right|=504 \mathrm{~m}^{2} \mathrm{a}^{-1}$ and $Y=2.5$. To obtain the $\Delta T_{0}$ for these values, we have to interpolate in each Table a-d the individual $\Delta T_{0}$ 's between columns (5) and (6) and plot them on logarithmic paper. From the plot $\Delta T_{0}=24.5 \mathrm{deg}$ is obtained for $\left|v_{H} H\right|=504$. This yields a $\Delta T=10.8 \mathrm{deg}$ which is in good agreement with the measured $\Delta T$.

Since in Camp Century there exists a measured temperature profile, we compare in Figure $\mathrm{I}$ the temperature profile obtained by the present theory with the measurement. Figure I also shows the temperature profiles obtained by Robin (I955) and Weertman (1968). For the special case of Camp Century, Weertman used the shear stress and the 
temperature to calculate $\partial v_{x} / \partial h$ and $v_{x}$. From our Equation (5) we obtain exactly the same $v_{x}$ profile. But Weertman does not use this $v_{x}$ profile to determine $v_{h}$ for the calculation of the temperature and age profiles. Instead he uses-as did Robin - the simpler equation $v_{h}=v_{H} h / H$ based on Nye's theory, which yields $v_{h}$ values which are too large. Therefore, the temperatures obtained by Robin and Weertman are too low (Fig. I) and the ages obtained by Nye's theory are too small (Fig. 2).

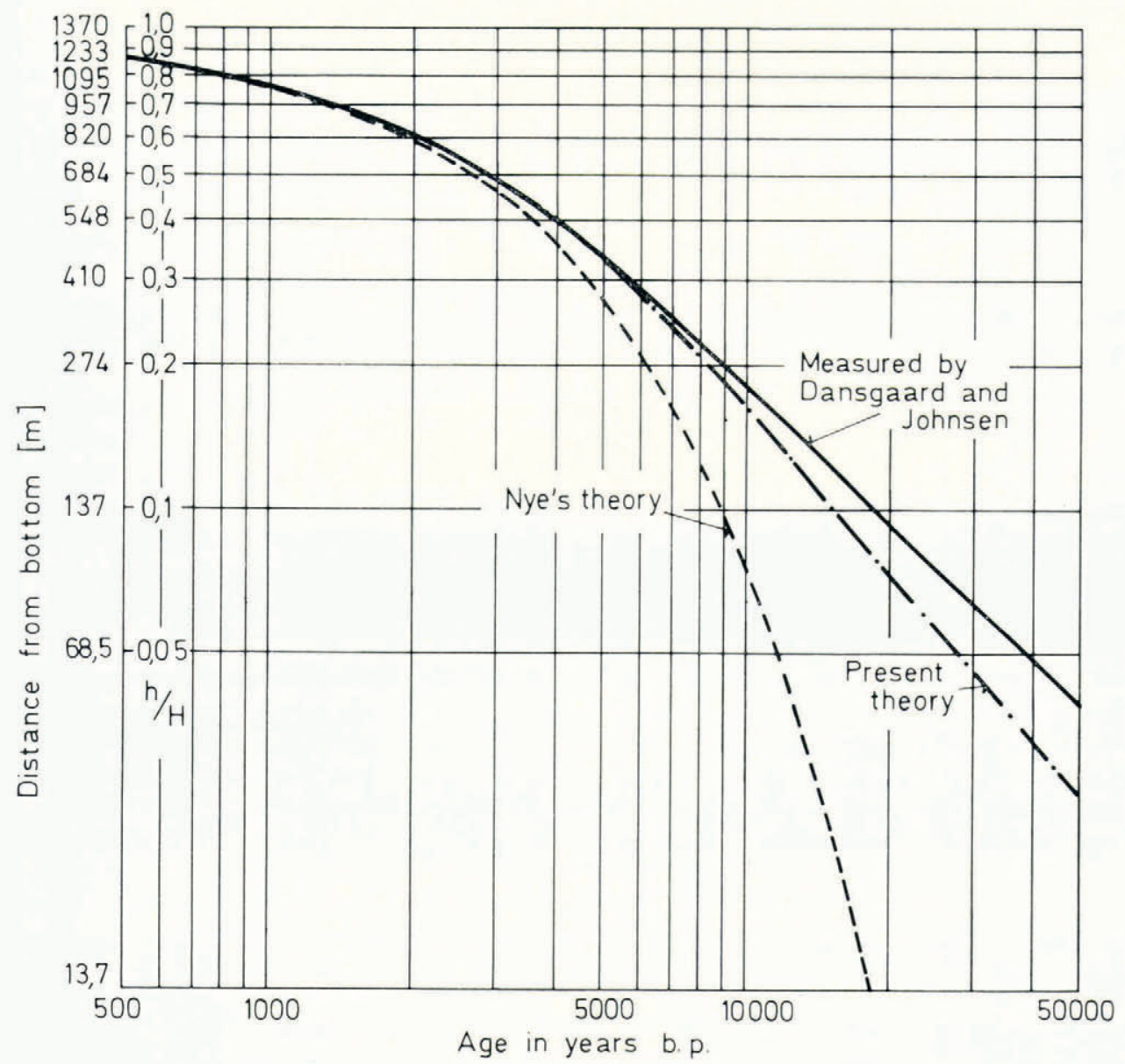

Fig. 2. Measured (by Dansgaard and Johnsen) and theoretical age profiles for the Camp Century bore hole. The distance in metres from bottom refers to a total ice value of $1370 \mathrm{~m}$.

Dansgaard and Johnsen ( $1969[\mathrm{a}]$ ) have used the measured age profile for the determination of the $v_{x}$ and temperature profiles (see below). The resulting curve does not differ appreciably from our temperature profile.

Figure 2 shows the age profiles. Dansgaard and Johnsen (ig69[b]) used for their calculation a linearized $v_{x}$ profile, the parameter $h$ of which is chosen such that their age profile is identical with their measured values. For the most important range below $300 \mathrm{~m}$ above the bedrock, this requires $v_{x}$ values which differ considerably from the $v_{x}$ profiles 
given by Weertman and by the present theory. The difference between the measurement and the present theory implies that, for the conditions at Camp Century, the value for the temperature coefficient $k$ must be smaller than $0 . \mathrm{I} \mathrm{deg}^{-1}$.

\section{Discussion}

In previous papers the profiles for the temperature and the age have been calculated from $v_{x}$-functions which have either been special cases (Dansgaard and Johnsen, I969[a], [b]) or rough approximations (Robin, I955). In contrast, Equation (5) is a relatively simple function for $v_{x}$ which sufficiently takes into account the influences of temperature and shear stress. Possibly there is no simpler function for $v_{x}$ which yields satisfactory temperature and age profiles for all real values of $H, A$ and $G$, because there exist ice sheets where the temperature influence is predominant (large $k G H$ ) and those where the shear-stress influence is predominant (small $k G H$ ) and those in between the two cases. The Tables and the examples show that the temperature and age profiles for these cases differ widely. In the columns (I) of the Tables the Nye flow model $\left(\partial v_{x} / \partial h=0\right)$ and in the columns $(7)$ the flow according to Glen's $\tau^{3}$-law are given as limiting cases $(k G H=\infty$ and $k G H=0$ respectively).

Equation (9) shows that $-v_{H}$ differs from $-A$ if $v_{x \mathrm{~m}}$ and $\partial H / \partial x$ are both non-zero. The temperature profile (I3) contains $v_{h}=v_{H} \psi(y, r)$, the age profile, however, $-A \psi(y, r)$. This difference can be viewed in the following way:

The surface receives the accumulation $A \mathrm{~d} t$ per unit time. Therefore each ice layer in the vicinity of the surface migrates by $A \mathrm{~d} t$ below the new surface. The increase in age $\mathrm{d} t$ of an ice layer in the surface region is thus equal to the distance from the surface divided by $A$. For deeper layers the product of $A$ with the normalized profile function $\psi(y, r)$ has to be taken instead of $A$.

The situation is quite different in the calculation of the temperature profile. The thermal interaction of the different ice layers depends on their relative separation which is calculated from the vertical velocity $v_{h}$. It is unimportant whether the separation between the layers is shortened because of the accumulation $A$ or because of their movement into a region with decreasing total height. Both influences together result in the quantity $v_{H}$ and therefore $v_{h}=v_{H} \psi(y, r)$ for the calculation of the temperature profile.

The temperature in the upper layers of ice sheets are influenced by short-time fluctuations of the climate. Furthermore, for $x=0$ the upper layers tend to have a small negative temperature gradient in the downward direction (de Quervain, I968, p. I76; Weertman, I968). Because of these reasons, the value of $T_{\mathrm{B}}$ calculated by Equation (14) becomes more realistic if it is possible to fit the calculated part of the profile to one measured down to a reasonable depth. This is done for the measured $\mathrm{I}$ ooo $\mathrm{m}$ profile at the E.G.I.G. station Jarl Joset in Greenland (to be published in Meddelelser om Gronland).

MS. received 3 September 1969 and in revised form 16 June 1970

\section{REFERENGES}

Budd, W. F. 1968. The longitudinal velocity profile of large ice masses. Union de Géodésie et Géophysique Internationale. Association Internationale d'Hydrologie Scientifique. Assemblée générale de Berne, 25 sept.-7 oct. 1967. [Commission de Neiges et Glaces.] Rapports et discussions, p. 58-77.

Dansgaard, W., and Johnsen, S. J. I969[a]. Comment on paper by J. Weertman, "Comparison between measured and theoretical temperature profiles of the Camp Century, Greenland, borehole". Fournal of Geophysical Research, Vol. 74, No. 4, p. I 109-10. [See also "Errata", Journal of Geophysical Research, Vol. 74.]

Dansgaard, W., and Johnsen, S. J. 1969[b]. A flow model and a time scale for the ice core from Camp Century, Greenland. Fournal of Glaciology, Vol. 8, No. 53, p. 21 5 -23.

Haefeli, R. I96r[a]. Contribution to the movement and the form of ice sheets in the Arctic and Antarctic. Fournal of Glaciology, Vol. 3, No. 30, p. 1 I $133^{-} 5^{1}$.

Haefeli, R. ig6r[b]. Eine Parallele zwischen der Eiskalotte Jungfraujoch und den grossen Eisschildern der Arktis und Antarktis. Geologie und Bauwesen, Jahrg. 26, Ht. 4, p. I9 I-2 I 3 
Haefeli, R. 1968. Gedanken zum Problem der glacialen Erosion. Rock Mechanics and Engineering Geology: Felsmechanik und Ingenieurgeologie, Suppl. 4, p. 31-51.

Hansen, B. L., and Langway, C. C., jr. Deep core drilling in ice and core analysis at Camp Century, Greenland, 1961-1966. Antarctic Journal of the United States, Vol. 1, No. 5, p. $207-08$.

Lliboutry, L. I968. Steady-state temperatures at the bottom of ice sheets and computation of the bottom ice flow law from the surface profile. Fournal of Glaciology, Vol. 7, No. 51, p. 363-76.

Nye, J. F. I951. The flow of glaciers and ice-sheets as a problem in plasticity. Proceedings of the Royal Society, Ser. A, Vol. 207 , No. IogI, p. 554-72.

Nye, J. F. 1952. A method of calculating the thicknesses of ice-sheets. Nature, Vol. 169, No. 4300, p. 529-30.

Nye, J. F. 1969 . The effect of longitudinal stress on the shear stress at the base of an ice sheet. Fournal of Glaciology, Vol. 8, No. 53, p. 207-13.

Philberth, B. 1956. Beseitigung radioaktiver Abfallsubstanzen. Atomkern-Energie (München), I. Jahrg., Ht. I I-I 2, p. $396-400$.

Philberth, K. 1970. Thermische Tiefbohrung in Zentralgrönland. Umschau in Wissenschaft und Technik, 1970, Ht. I6, p. $5^{1} 5^{-16}$.

Philberth, K., and Federer, B. 1970. A note on the surface profile of the Greenland ice sheet. Fournal of Glaciology,

Vol. 9, No. 55, p. ${ }^{150-53 .}$
Quervain, M. R. de. 1968 . Schneekundliche Arbeiten der Internationalen Glaziologischen Grönlandexpedition (EGIG). Meddelelser om Grenland, Bd. 177, Nr. 4 .

Ramseier, R. O. Unpublished. Self-diffusion in ice monocrystals. [M.A. thesis. Dartmouth College, Hanover, New Hampshire, 1967.$]$

Robin, G. de Q. 1955. Ice movement and temperature distribution in glaciers and ice sheets. Fournal of Glaciology, Vol. 2, No. 18, p. 523-32.

Weertman, J. 196r. Equilibrium profile of ice caps. Journal of Glaciology, Vol. 3, No. 3o, p. $953-64$.

Weertman, J. 1968. Comparison between measured and theoretical temperature profiles of the Camp Century, Greenland, borehole. Fournal of Geophysical Research, Vol. 73, No. 8, p. 269i-700.

\section{APPENDIX A}

Above a certain height the linear form of Equation (2) differs considerably from the true temperature profile. As a characteristic height where the deviation becomes important, we take $h_{\mathrm{c}}$ which is the height of maximum curvature of the temperature profile. $h_{\mathrm{c}}$ can be calculated by use of the Equation (12a)

$$
\frac{\partial^{2} T}{\partial h^{2}}=\frac{v_{h}}{\kappa} \frac{\partial T}{\partial h} \text {. }
$$

Differentiating with respect to $h$, the left-hand side becomes zero at the maximum of the curvature:

$$
\mathrm{o}=\frac{\partial^{2} T}{\partial h^{2}} \frac{v_{h}}{\kappa}+\frac{1}{\kappa} \frac{\partial T}{\partial h} \frac{\partial v_{h}}{\partial h} .
$$

Using Equation $\left(A_{1}\right)$ in $\left(A_{2}\right)$ yields:

$$
\mathrm{o}=\frac{\partial T}{\partial h}\left(\frac{v_{h}}{\kappa}\right)^{2}+\frac{1}{\kappa} \frac{\partial T}{\partial h} \frac{\partial v_{h}}{\partial h}
$$

or

$$
v_{h}^{2}=-\kappa \partial v_{h} / \partial h \text {. }
$$

If we use the approximate expression $v_{h}=-A h / H$ we arrive at the relationship described in the Introduction:

$$
\begin{aligned}
v_{h \mathrm{c}} h_{\mathrm{c}} & =-\kappa \\
h_{\mathrm{e}} & =(\kappa H / A)^{\frac{1}{2}} .
\end{aligned}
$$

(The indices $c$ denote the point of maximum curvature.)

Thus, from the bedrock to $h_{\mathrm{c}}$ the linear form (Equation (2)) is a very good approximation for the true temperature profile.

Above $h_{\mathrm{c}}$ the deviation is large. If we want to use Equation (2) in the calculations of the horizontal and vertical velocity profiles, we must prove that, above $h_{\mathrm{c}}$, the temperature does not influence the $v_{x}$ profile to any appreciable extent. In order to prove this, we will show that at $h_{\mathrm{c}}$ the shear velocity $\partial v_{x} / \partial h$ has decreased by at least a factor $\mathrm{I} / \mathrm{e}=0.368$ with respect to its value at the bedrock (in most real situations the factor is essentially smaller than this). If this is the case the increase of $v_{x}$ between $h_{\mathrm{c}}$ and the surface $(h=H)$ is very small. Therefore we are not committing any important errors by using the linear form (2) which, above $h_{\mathrm{c}}$, yields a lower temperature and therefore a larger rigidity of the ice than the true values. A larger rigidity above $h_{\mathrm{e}}$, however, further reduces the difference of $v_{x}$ between $h=h_{\mathrm{e}}$ and $h=H$.

Suppose now that the shear strain-rate (Equation $(5)$ ) has decreased by a factor less than $\mathrm{I} / \mathrm{e}$. Division of Equation (5) for $h=h_{\mathrm{c}}$ by the value for $h=0$ yields:

$$
\left\{\left(H-h_{\mathrm{c}}\right) / H\right\}^{3} \exp \left(-k G h_{\mathrm{c}}\right)<\mathrm{I} / \mathrm{e} .
$$

From Equation (A5), $k G h_{\mathrm{c}}=k G h_{\mathrm{c}}^{2} / h_{\mathrm{c}}=\frac{k G \kappa H}{A h_{\mathrm{c}}}$ and inserting this into inequality (A6) we obtain:

$$
\left(\mathrm{r}-h_{\mathrm{c}} / H\right)^{3} \exp \left(-\frac{k G \kappa H}{A h_{\mathrm{c}}}\right)<\mathrm{r} / \mathrm{e} .
$$


If condition $\left(\mathrm{A}_{7}\right)$ is fulfilled, the linear form (2) can be used in calculating the velocity and temperature profiles. It can be seen that $\left(\mathrm{A}_{7}\right)$ is fulfilled for every possible value of $h_{\mathrm{c}} / H$ if

$$
A / k G_{\kappa} \leqslant \mathrm{I} 2
$$

The magnitude of the error in Equation (5) cannot very well be estimated by using the foregoing considerations. The error is equal to the difference $D$ between the real value of $\partial v_{x} / \partial h$ and the one given by Equation (5). The function $D$ depends on the true temperature profile, which can be calculated by Equation $\left(\mathrm{A}_{\mathrm{I}}\right)$. In this way the following approximation is obtained:

$$
D \approx f(x) H^{3} \exp (-Y h / H)(h / H)^{3} Y^{2} A /(6 k G \kappa) .
$$

The precise calculations show that the neglected terms of higher order (in the temperature function and in the exponential expression) nearly compensate each other, so that Equation (Ag) is rather accurate for all real ice sheets.

Comparing Equation (5) with the function $f(x)(H-h)^{n} \exp (-k T)$, where $T$ is the real temperature profile and $n$ is chosen such that the values of this function are equal in the region where $D$ has its maximum, yields the exponents $n$ given in Table III.

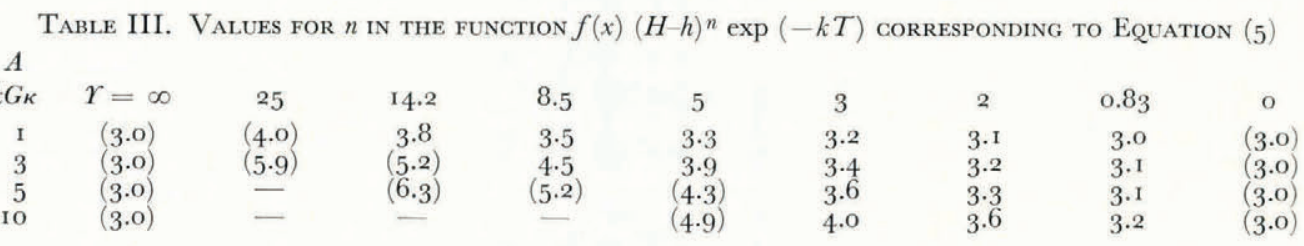

Numbers in brackets are $n$-values for unreal ice sheets. Only Antarctica and Greenland have $\gamma$-values $>3$; but for these ice sheets $A$ is smaller than $0.35 \mathrm{~m} \mathrm{a}^{-1}$, and therefore $A /(k G \kappa) \leqslant 3$. Thus, for all existing ice sheets $n$-values between 3 and 5 are obtained.

These estimates need the following comment: Robin's treatment is the zeroth approximation to the velocity profile, because the temperature is not taken into account and $n$ is taken to be $\infty$. Equation (5) with the linear temperature profile is the first approximation if the exponent in Glen's law is taken to be 3. On the other hand, Equation (5) is already the second approximation if it is taken to describe the true physical mechanism with the real temperature profile instead of $-G h$ and an exponent $n$ taken from Table III.

Since laboratory and field experiments yield an exponent $n$ between 3 and 4 , we arrive at the following conclusion: Equation (5) gives a very accurate description of the temperature profile for all ice sheets; in many cases (especially if $n \approx 3.5$ ) the description of the temperature profile by Equation (5) is even better than if one had substituted $-G h$ by the true temperature profile.

\section{APPENDIX B}

In this Appendix it is shown that, because of assumption (6), it is justified to put $\tau_{x h}$ for $\tau$ in Equation ( 1 ) and $\partial v_{x} / \partial h$ for $\dot{\epsilon}$. In recent papers (Budd, I968; Nye, 1969) detailed studies on the stress in ice sheets have been published. Here an intuitive description of the ice flow is given. The ice sheet is considered to consist of a pile of thin horizontal layers. These are subject to the shear stress $\tau_{x h}$ and the shear strain-rate $\partial v_{x} / \partial h$ between the layers and to the longitudinal stress $\sigma_{x}-\sigma_{h}$ and the longitudinal strain-rate $\partial v_{x} / \partial x-\partial v_{y} / \partial y=2 \partial v_{x} / \partial x$ within the layers.

At the ice divide $(x=0) \alpha, v_{x}, \partial v_{x} / \partial h$ and $\tau_{x h}$ are zero; $\sigma_{x}-\sigma_{h}$ and $2 \partial v_{x} / \partial x$ are non-zero. Therefore for the ice divide we can state that the longitudinal stress $\sigma_{x}-\sigma_{h}$ drives the longitudinal strain-rate $2 \partial v_{x} / \partial x$ and the shear stress $\tau_{x h}$ drives the shear strain rate $\partial v_{x} / \partial h$. This statement is approximately valid for the whole central region of the ice sheet. In order to prove this fact we consider, as a first approximation, not only $T$ but also $2 \partial v_{x} / \partial x$ to be independent of $x$ and consequently the longitudinal stress for the maintenance of $2 \partial v_{x} / \partial x$ to be likewise independent of $x$. This last mentioned longitudinal stress and the longitudinal stress $\sigma_{x}-\sigma_{h}$ both being independent of $x$ and both being identical for $x=0$ we can conclude that they are identical also for $x \neq 0$.

There could be an objection: for our proof we have neglected some values which have been called small. For large values of $x$ these could add up to an amount which could be not negligible. In principle this objection is right. It must be realized, however, that $\sigma_{x}-\sigma_{h}$ and $2 \partial v_{x} / \partial x$ are nearly independent of $x$ while $\tau_{x h}$ and $\partial v_{x} / \partial h$ increase with $x$. Calculations have shown that under conditions which exist on the E.G.I.G. profile in central Greenland, for $x>$ Io $H$ the longitudinal force (i.e. $\sigma_{x}-\sigma_{h} \approx 2 \sigma_{x}-p_{\text {s }}$ integrated over a vertical cross-section) is smaller than the total shear force (i.e. the bottom value of $\tau_{x h}$ integrated over a horizontal cross-section). In consequence, even if an influence of $\sigma_{x}-\sigma_{h}$ on $\partial v_{x} / \partial h$ exists, this influence remains small with respect to that of $\tau_{x h}$. $\dot{\epsilon}$ and $\tau$ in Equation (I) can therefore be understood as $\partial v_{x} / \partial h$ and $\tau_{x h}$ respectively. In Nye's (I 669 ) equation (3) $\frac{\partial \sigma_{x}}{\partial x}+\frac{\partial \tau_{x h}}{\partial h}+\rho g \sin \alpha=0, \partial \sigma_{x} / \partial x$ can be neglected because $\sigma_{x} \approx\left(\sigma_{x}-\sigma_{h}+p_{\mathrm{s}}\right) / 2$, where $p_{\mathrm{s}}$ is nearly independent of $x$, so that it reads

$$
\partial \tau_{x h} / \partial h=-\rho g \sin \alpha
$$

